\title{
Christian Gomille
}

\section{Informationsproblem und Wahrheitspflicht}

\author{
Ein Aufklärungsmodell für den Zivilprozess
}

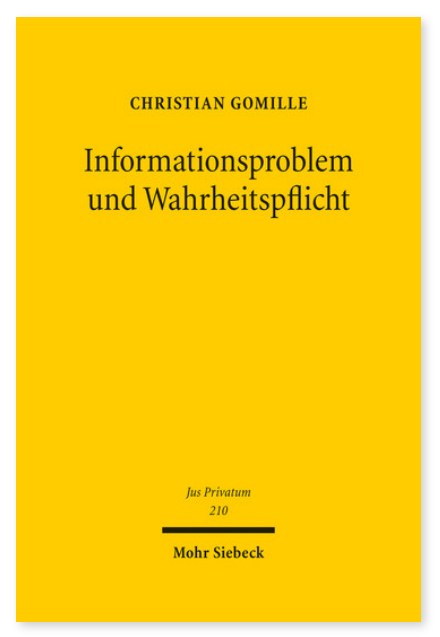

2016. XXV, 506 Seiten. JusPriv 210

ISBN 978-3-16-154612-9

DOI 10.1628/978-3-16-154612-9

eBook PDF 129,00€

ISBN 978-3-16-154611-2

Leinen $129,00 €$
Im deutschen Zivilprozessrecht hat nach wie vor jede Partei das Tatsachenmaterial zu beschaffen, das zu einer für sie günstigen Entscheidung führt. Die nicht oder nicht vollständig informierte Partei kann diese Aufgabe gegebenenfalls nicht erfüllen und verliert in der Folge den Prozess. Eine wesentliche Ursache dieses Informationsproblems liegt darin, dass der Gegner in gewissem Umfang selbst steuern kann, welche Informationen die risikobelastete Partei benötigt, und zwar indem er wahrheitswidrig bestreitet. Wirksame Mechanismen gegen diesen Wahrheitsverstoß existieren bislang nicht. Bei dem Versuch, die größten Härten des Informationsproblems abzumildern, hat sich im Lauf der Zeit eine unübersichtliche und teils in sich widersprüchliche Gemengelage von Regeln und Ausnahmen etabliert. Dem setzt die Untersuchung einen Entwurf für ein prozessrechtliches Aufklärungsmodell entgegen, das bei der Wahrheitspflicht der Parteien ansetzt und dem Gegner die Steuerungsmöglichkeit über das Informationsproblem der risikobelasteten Partei entzieht.

Christian Gomille Geboren 1977; Studium der Rechtswissenschaften in München; Referendariat in München und Paris; Rechtsanwalt in einer auf IT- und Medienrecht spezialisierten Kanzlei; wissenschaftlicher Mitarbeiter an der LudwigMaximilians-Universität München; 2009 Promotion; 2015 Habilitation; seit 2012 Juniorprofessor für Bürgerliches Recht sowie deutsches und internationales Zivilverfahrensrecht, Universität Augsburg.

Jetzt bestellen:

https://mohrsiebeck.com/buch/informationsproblem-und-wahrheitspflicht-9783161546129?no_cache=1 order@mohrsiebeck.com

Telefon: +49 (0)7071-923-17

Telefax: $+49(0) 7071-51104$ 